\title{
ESTRATÉGIAS DE GESTÃO AMBIENTAL E SEUS FATORES DETERMINANTES: UMA ANÁLISE INSTITUCIONAL
}

ENVIRONMENTAL MANAGEMENT STRATEGIES AND THEIR DETERMINANT FACTORS: AN INSTITUTIONAL ANALYSIS

ESTRATEGIAS DE GESTIÓN AMBIENTAL Y SUS FACTORES DETERMINANTES: UN ANÁLISIS INSTITUCIONAL

\section{RESUMO}

O objetivo deste trabalho consiste em analisar os fatores determinantes das estratégias de gestão ambiental das empresas industriais catarinenses. Os dados primários foram obtidos por meio de um questionário respondido por 88 empresas e analisados quantitativamente por meio da análise descritiva e de correspondência múltipla. O estudo demonstrou que os fatores internos determinantes das estratégias de gestão ambiental foram o comprometimento dos colaboradores e o apoio dos gestores e, os externos, as exigências da sociedade, as regulamentações governamentais, a adequação aos padrões normativos e a concorrência. A pesquisa também aponta para um mimetismo que ainda não foi rompido pelas empresas mais proativas, denotando uma homogeneidade na interpretação do ambiente institucional por parte das empresas.

PALAVRAS-CHAVE Institucionalismo, legitimidade, gestão ambiental, orientação estratégica, mimetismo.

Graziela Dias Alperstedt gradial@gmail.com

Professora da Escola Superior de Administração e Gerência, Universidade do Estado de Santa Catarina, Florianópolis - SC, Brasil

Rogério Hermida Quintella rhquintella@gmail.com

Professor titular da Escola de Administração, Universidade Federal da Bahia, Salvador - BA, Brasil

Luiz Ricardo Souza luizricardo.souza@gmail.com

Graduando em Administração Pública pela Escola Superior de Administração e Gerência, Universidade do Estado de Santa Catarina, Florianópolis - SC, Brasil

Recebido em 29.05.2009. Aprovado em 23.04.2010

Avaliado pelo sistema double blind review. Editores Científicos: José Carlos Barbieri, Isabella Freitas Gouveia de Vasconcelos, Tales Andreassi e Flávio Carvalho de Vasconcelos

ABSTRACT The objective of this paper is to analyze the factors that determine the environmental management strategies of industrial companies from Santa Catarina. Primary data were obtained from a questionnaire replied to by 88 companies and quantitatively analyzed by means of multiple correspondence analysis. The study showed that the internal factors that determine environmental management strategies were employee commitment and managerial support and the external factors were society demands, government regulations, adjustment to normative standards and competition. The research also indicates there is a mimetic process which the most proactive companies are still unable to avoid, denoting that there exists a degree of homogeneity in these companies' interpretation of the institutional environment.

KEYWORDS Institutionalism, legitimacy, environmental management, strategic orientation, mimetic processes.

RESUMEN El objetivo de este trabajo consiste en analizar los factores determinantes de las estrategias de gestión ambiental de las empresas industriales del estado de Santa Catarina. Los datos primarios fueron recolectados a través de un cuestionario respondido por 88 empresas y analizados cuantitativamente por medio del análisis descriptivo y de correspondencias múltiples. El estudio mostró que los factores internos determinantes de las estrategias de gestión ambiental fueron el compromiso de los colaboradores y el apoyo de los gestores y los externos, las exigencias de la sociedad, las reglamentaciones gubernamentales, la adecuación a los estándares normativos y la competencia. La investigación también apunta a un mimetismo que todavía no ha sido quebrado por las empresas más proactivas, lo que denota una homogeneidad en la interpretación del ambiente institucional de parte de las empresas.

PALABRAS CLAVE Institucionalismo, legitimidad, gestión ambiental, orientación estratégica, mimetismo. 


\section{INTRODUÇÃO}

Uma das primeiras publicações importantes a tratar da necessidade de se repensar o modelo de desenvolvimento enfatizando questões ambientais foi Social Responsibilities of the Businessman, de Howard R. Bowen, em 1953 (NASCIMENTO, 2007). Todavia, a temática ambiental passou a repercutir globalmente a partir da publicação de A primavera silenciosa, de Rachel Carson, em 1962, livro que enfatiza os malefícios da utilização de pesticidas. A partir daquele momento, houve um significativo crescimento no interesse popular e gerencial a respeito da questão ambiental, paralelamente ao surgimento de legislações ambientais mais rigorosas em todo o mundo. Até esse período, a questão ambiental era compreendida estritamente como geradora de custos adicionais, não produzindo benefício visível às empresas.

A segunda onda do ambientalismo corporativo foi impulsionada pelo acidente na cidade indiana de Bhopal, em 1984, causado pela emissão de gás venenoso que escapou de uma fábrica de pesticidas de propriedade da Union Carbide, de origem norte-americana, e tido com um dos piores desastres industriais da história, provocando a morte de milhares de pessoas. Após esse acidente, a visão da sociedade alterou-se de forma mais acentuada, exigindo respostas por parte das empresas.

Pressionadas pelas demandas sociais, as mudanças na postura industrial na década de 1980 foram evidenciadas na multiplicação dos chamados "selos verdes". Os primeiros "selos verdes" ainda se apoiavam em critérios simples, como a redução ou a eliminação de uma ou mais substâncias poluentes mais significativas do produto. A evolução se deu observando critérios de redução do impacto ambiental desde a produção até o descarte final, compreendendo assim o ciclo de vida dos produtos.

Baseada nas questões de valor, a terceira fase desse movimento iniciou-se na década de 1990. Desde então, uma visão mais sistêmica da questão tem se tornado regra, permitido a muitas organizações constatar que os consumidores desejavam empresas que trabalhassem com base em valores ambientais, demonstrando uma nova perspectiva (ABREU, 2001). A partir desse período, tem crescido a preocupação com a forma de se fazer negócios, buscandose incluir na gestão o cuidado com o ambiente natural e o atendimento às demandas dos diversos públicos com os quais as organizações se relacionam. Apesar disso, a introdução das questões ambientais no escopo dos negócios não tem ocorrido da mesma forma nas diferentes organizações e regiões. Para Jabbour e Santos (2006), tais diferenças tendem a relacionar-se à natureza das organizações, bem como às atitudes dos seus gestores. Considerando tal constatação, parece natural que organizações de maior porte tenham distintas formas de se relacionar com essas questões quando comparadas às menores, quer por sua maior sofisticação gerencial, quer por simples diferenças de possibilidades financeiras. Nesse sentido, questionase: a) quais os fatores percebidos pelas empresas como determinantes das suas estratégias de gestão ambiental? b) existem diferenças na percepção desses aspectos em função do porte da empresa?

Tendo em vista a problemática apresentada, e considerando a importância de se conhecer a realidade do estado de Santa Catarina em função de sua relevância industrial para o país, este artigo se propõe a analisar os fatores determinantes das estratégias de gestão ambiental adotadas pelas empresas industriais catarinenses. O estudo justifica-se não apenas em função da preocupação da sociedade em relação ao ambiente natural e das ações das empresas nesse campo, como também em função da carência de pesquisas empíricas que incluam empresas brasileiras de vários tamanhos e setores. De forma específica, este artigo busca atender à carência de pesquisas que incluam desde as pequenas empresas (LEE, 2009) até as grandes, propiciando uma análise a partir da perspectiva cognitiva da teoria neoinstitucional.

Além desta Introdução, o artigo estrutura-se em quatro outras seções, que abordam os construtos teóricos que sustentam a pesquisa, os procedimentos metodológicos utilizados na investigação, a apresentação dos resultados e as discussões e considerações finais do estudo.

\section{FUNDAMENTOS TEÓRICOS}

\section{Estratégias de gestão ambiental e seus aspectos determinantes}

Nos últimos anos, tem crescido o número de estudiosos que argumentam que, para alcançar vantagem competitiva, torna-se necessário que as empresas maximizem seu retorno ao mesmo tempo que desenvolvem progressos em relação à implementação de práticas ambientais nos negócios (LEE, 2009; BERRY; RONDINELLI, 1998; PORTER; VAN DER LINDE, 1995). Essa conexão é baseada no número de pesquisas que concluíram que uma estratégia ambiental proativa lidera o desenvolvimento de importantes capacidades organizacionais que podem elevar a competitividade das indústrias (ARAGON-CORREA; SHARMA, 2003; BERRY; RONDINELLI, 1998; SHARMA; VREDENBERG, 1998). Como resultado, muitos estudiosos da literatura corrente têm concluído que as empresas 
precisam incorporar questões relativas ao ambiente natural no âmago de suas estratégias competitivas.

A gestão ambiental, de acordo com D'Avignon (1996), é a "parte da função gerencial que trata, determina e implementa a política de meio ambiente estabelecida para a empresa". O termo "política ambiental" é definido pela norma NBR Série ISO 14001 como "a declaração da organização, expondo suas intenções e princípios em relação ao seu desempenho ambiental global, que provê uma estrutura para a ação e definição de seus objetivos e metas ambientais". Nesse sentido, ela estabelece a orientação e fixa os princípios de ação para a organização. Reis e Queiroz (2002), por sua vez, definem política ambiental como uma declaração de comprometimento empresarial com o meio ambiente, sendo a base do sistema de gestão da empresa.

Já no que tange às diferenças de comportamento das organizações em relação ao ambiente, Abreu e outros (2008), González-Benito e González-Benito (2006) e Christmann e Taylor (2001) constataram que o tamanho, mensurado pelo número de empregados ativos, é uma das variáveis estruturais que mais parece influenciar nas ações ambientais das empresas. O argumento usado por eles baseia-se em diferentes aspectos: 1) grandes empresas têm mais recursos disponíveis para investir na gestão ambiental; 2) elas recebem maior pressão dos ambientes social e econômico e freqüentemente são objetivo primário de governos locais e ONGs ambientais; 3) sua escala permite que sua gestão se torne indivisível da gestão ambiental, requerendo investimentos em tecnologia, recursos humanos ou certificações que são similares para todas as empresas independentemente do seu tamanho; e 4) os esforços ambientais das grandes empresas têm um impacto positivo sobre um grande número de clientes. Por outro lado, Lee (2009) constatou que as pequenas e médias empresas possuem algumas vantagens quando comparadas às grandes, no que se refere à gestão ambiental efetiva. Pequenas empresas possuem canais de comunicação mais informais, suas estruturas são mais flexíveis, as pessoas são multifuncionais e o acesso aos gestores de topo é mais facilitado.

Na visão de Schenini (2005), a adoção de medidas ambientalmente responsáveis é motivada por razões internas e externas das organizações. Dentre as razões internas estão a diminuição de custos, a atualização tecnológica, a otimização nos processos produtivos e o desenvolvimento de uma cultura interna ecologicamente correta. No que concerne às razões externas estão a tendência à prevenção de acidentes ecológicos por parte da sociedade e as demandas das partes interessadas, principalmente de agências financiadoras, comunidade local, organizações da sociedade civil e governo. Souza (2002) destaca, além das regulamentações ambientais, dos mercados e das fontes de recursos, o papel da sociedade civil organizada, principalmente através dos movimentos ambientalistas.

$\mathrm{Na}$ onda da assim chamada teoria dos stakeholders (FREEMAN, 1984), a influência das partes interessadas é citada por Berry e Rondinelli (1998) e Bansal e Roth (2000) como responsáveis pela adoção da gestão ambiental proativa por parte das empresas que, buscando satisfazê-las, têm descoberto que uma estratégia proativa requer mais que um simples ajustamento às políticas governamentais. González-Benito e González-Benito (2006) se remetem a Clarson (1995) para fazer a distinção entre o que ele denomina stakeholders primários e secundários. Os primários são indivíduos ou grupos cuja participação e suporte são essenciais para a sobrevivência das empresas. Entre eles estão os consumidores, os fornecedores e os órgãos regulamentadores. Já os secundários afetam e são afetados pela organização, mas não estão engajados nas transações organizacionais, sendo, portanto, não essenciais para a sobrevivência da organização, como, por exemplo, a mídia e as organizações ambientalistas.

Já Hart (1995), ao observar a teoria organizacional, destaca que esta trata o conceito de ambiente enfatizando os fatores políticos, econômicos, sociais, tecnológicos, dentre outros, porém, excluindo o ambiente natural da análise estratégica. Para ele, essa omissão torna a teoria inadequada para identificar importantes fontes de vantagem e desvantagens competitivas originadas no ambiente natural. A partir dessa observação, Hart propõe uma teoria baseada em recursos naturais, que seria desenvolvida tomando como base os desafios ambientais e os recursos das firmas operacionalizados a partir de três estratégias de gestão ambiental, que seriam, simplificadamente: a prevenção da poluição, o planejamento do produto e o desenvolvimento sustentável.

Diversas outras classificações são descritas pelos autores variando em termos de número de níveis para caracterizar a preocupação das empresas com a questão ambiental (ROHRICH; CUNHA, 2004; JABBOUR; SANTOS, 2006). De forma geral, são destacados três níveis: o primeiro nível refere-se ao controle da poluição, quando a empresa procura adaptar-se às pressões normativas e às exigências do mercado. O segundo nível corresponde à prevenção da poluição, requerendo alterações nos processos produtivos e nos produtos produzidos. Já o terceiro nível caracterizase por ações mais proativas, envolvendo permanentemente toda a cadeia produtiva, assim como toda a organização, em ações corretivas, preventivas e antecipatórias diante da possibilidade de problemas ambientais (BARBIERI, 2004; DONAIRE, 1995; MAIMON, 1994). Por outro lado, Hunt 
e Auster (1990) apresentam uma classificação de cinco estágios que variam desde a ausência ou presença limitada de ações de gestão ambiental até a presença de programas difundidos por toda a empresa, inclusive a educação dos colaboradores, o monitoramento constante das informações e a resolução rápida de problemas. Quando as questões ambientais alcançam este último nível, elas passam a ser incorporadas nas metas, políticas e estratégias da empresa considerando o impacto ambiental de seus processos e produtos. Sanches (2000) classifica esse comportamento como proativo. Vale ressaltar que a taxonomia de Sanches (2000), diferentemente da de Hunt e Auster, classifica as organizações em apenas dois estágios: um reativo e outro proativo. Trazendo essa discussão para o ambiente empresarial brasileiro, Rohrich e Cunha (2004) concluíram, em sua pesquisa, que as organizações brasileiras têm demonstrado diferente comportamento no que tange às questões relativas à gestão ambiental. Mesmo nos casos em que observaram a existência de um 'sistema de gestão ambiental' certificado conforme a NBR ISO 14.001, os autores identificaram diferenças de comportamento gerencial consideráveis entre as organizações.

Esta breve revisão mostra que há uma ampla frente de estudiosos para os quais as estratégias voltadas à gestão ambiental podem trazer vantagens competitivas para as organizações. Callenbach e outros (1993), por sua vez, agregam o conceito de sustentabilidade e, mais especificamente, a questão do retorno financeiro à discussão, ao afirmarem que, por meio da sustentabilidade ambiental, as organizações podem garantir sua rentabilidade de longo prazo e utilizá-la como critério para posicionamento estratégico. Sobre esses aspectos, Molina e outros (2009) descrevem uma pesquisa em 32 artigos de natureza quantitativa em periódicos especializados que mostra que o real comprometimento das empresas com as causas ambientais se relaciona com retornos financeiros positivos.

A derivação desses estudos e conclusões para as práticas operacionais, por sua vez, implica mudanças nos sistema de produção e operação das empresas. Para Gupta (1994), as práticas operacionais de implicações ambientais podem ser classificadas em dois grupos: práticas relacionadas aos produtos e práticas relacionadas aos processos. O primeiro grupo inclui práticas focadas nos esforços de design que buscam a eliminação de poluentes e materiais perigosos nos produtos. Como exemplo, podem-se citar os esforços empreendidos na eliminação do uso de materiais poluentes e perigosos, reduzindo o consumo de recursos na produção, bem como seu uso nos produtos ou na sua destruição ou desmontagem, elevando a reutilização e a reciclagem. O segundo grupo, das práticas relacionadas aos processos, tem seu foco no desenvolvimento e na implementação de uma maior consciência na produção, nos métodos e nos processos operacionais. Alguns deles afetam processos internos e incluem práticas de remediação e controle (por exemplo, a instalação de filtros de emissão ou sistemas de separação de resíduos) conjuntamente com práticas preventivas (uso de energias renováveis ou aquisição de tecnologias limpas).

Feita essa discussão preliminar das questões relativas à gestão ambiental, a próxima seção conduz à interface dessas questões com a teoria organizacional neoinstitucionalista.

\section{A teoria neoinstitucional e suas contribuições para a análise das questões ambientais}

A revisão apresentada na seção anterior traz à tona a necessidade de discutir os aspectos institucionais da questão ambiental no contexto organizacional. Nesse sentido, a teoria neoinstitucional permite agregar à discussão sua visão sociológica, reconhecendo não somente a ação prática como aspecto importante nos processos de institucionalização, como também o papel do ambiente como elemento constitutivo das organizações (DIMAGGIO; POWEL, 1983, 1991, 2005; MEYER; SCOTT, 1983).

A busca da legitimidade tem papel central na explicação das práticas organizacionais (ZUCKER, 1987; SELZNICK, 1996), e sua importância é especialmente destacada na obra de Meyer e Rowan (1977), para os quais as organizações que absorvem aspectos racionais socialmente legítimos na sua estrutura formal aumentam a sua legitimidade e capacidade de sobrevivência. Essa perspectiva, para Ogawa (1994), considera que o comportamento dos atores, tanto individuais quanto coletivos, resulta da influência de instituições tais como regras sociais, que acabam formando as teorias culturais, as ideologias dominantes e as prescrições sociais. A pressão exercida para que as organizações se conformem a essas regras e normas acaba guiando seu comportamento, que tenderá a ser compatível com as forças institucionais. A preocupação em se conformar às regras e normas ditadas pelo ambiente originaria, desse modo, uma uniformidade nas organizações. Essa tendência à similaridade de forma e estrutura em relação ao ambiente institucional é denominada isomorfismo (ZUCKER, 1987).

O isomorfismo institucional, como é amplamente conhecido na área dos Estudos Organizacionais, é, para DiMaggio e Powell (1983; 1991), o grande responsável pela homogeneidade estratégica das organizações, podendo ocorrer a partir de três mecanismos: (1) das forças coercitivas do ambiente; (2) do mimetismo; e (3) das pressões normativas. As forças coercitivas do ambiente são derivadas das influências políticas, das regulações 
governamentais e das forças culturais da sociedade. Tais pressões estão relacionadas ao pilar regulatório de Scott (2001), e ligam-se à legitimidade, incluindo tanto pressões formais quanto informais, como os hábitos de vida de uma sociedade ou a negação no desempenho de alguma ação. Para os autores, o processo mimético é a segunda forma como o isomorfismo ocorre. Esse tipo de isomorfismo se dá em resposta às incertezas ambientais. As organizações buscam respostas às incertezas com base na forma como outras organizações enfrentam as mesmas incertezas ambientais. Por fim, uma terceira fonte de isomorfismo é aquela que ocorre por decorrência das pressões normativas que se originam da profissionalização da força de trabalho, especialmente da gerência, pois, à medida que as pessoas participam de associações profissionais e de negócios, suas ideias tendem a ser homogêneas. Desse modo, elas acabam modelando suas organizações de modo a parecerem uniformes (DIMAGGIO; POWEL, 1983; OGAWA, 1994).

Assim, a aceitação dos processos de isomorfismo acaba por constituir uma visão determinística da teoria neoinstitucional, contrapondo-se, portanto, à visão da escolha estratégica. Para solucionar esse problema, alguns pesquisadores têm argumentado que, apesar de os contextos ambientais serem altamente institucionalizados, os processos sociais e cognitivos são, ainda, orientadores do fundamento da ação, dando relevo à sua capacidade de agência (OLIVER, 1991; HALL; TAYLOR, 2003; GIDDENS, 2003; SHARMA, 2000)Para muitos autores, portanto, o ambiente é percebido, interpretado e avaliado pelos atores organizacionais, sendo as condições ambientais importantes na medida em que são percebidas como significativas pelos decisores (HALL, 1990). Esses significados, atribuídos pelos atores, podem, todavia, ter origem no próprio contexto social, reconhecendo a natureza recursiva dessa relação, uma vez que o próprio ambiente institucional é constituído por atores organizacionais em interação (MACHADODA-SILVA; FONSECA; FERNANDES, 1999).

A institucionalização, assim, seria o processo a partir do qual os atores (individuais ou coletivos) transmitem o que é socialmente aceito como real. Tendo como base esses argumentos, é possível admitir-se que a gestão ambiental seja conduzida tanto por pressões institucionais do ambiente quanto pela escolha dos atores organizacionais, cuja influência se origina no próprio contexto social.

\section{PROCEDIMENTOS METODOLÓGICOS}

A pesquisa utiliza os fundamentos da abordagem quantitativa e exploratória e pode ser caracterizada como um levantamento de campo tipo survey. O survey permite a coleta de informações a partir de indivíduos a respeito de questões relacionadas a assuntos ligados a eles ou às organizações em que atuam (FORZA, 2002).

A coleta de dados secundários se deu por meio de materiais informativos já disponíveis em relatórios de pesquisas anteriores, bem como em documentos institucionais da Federação das Indústrias do Estado de Santa Catarina (FIESC), revistas especializadas, leis e regulamentações ambientais. Após o exame do material coletado que permitiu um entendimento da realidade estudada, partiu-se para a coleta de dados primários por meio de um questionário aplicado junto aos responsáveis pela área ambiental das empresas, focando os aspectos relacionados ao objetivo da pesquisa. O contato com as empresas foi realizado por meio da área de Competitividade Industrial (COI) da FIESC, e o questionário foi respondido on-line através de um link pelo sistema virtual da FIESC de forma autoadministrada (HAIR JR. e outros, 2005).

O questionário foi planejado tendo como base os fundamentos teóricos apresentados. Em sua primeira versão, ele foi analisado por dois especialistas na área de gestão ambiental de empresas e pela área de Competitividade Industrial da FIESC para verificação da pertinência do instrumento. Com essa análise, foram obtidas 10 sugestões de melhoria. Além de aspectos concernentes às opções de resposta, houve a indicação, pela FIESC, de redução do tamanho do questionário, alegando falta de tempo dos respondentes. Após essa etapa, foi aplicado um teste piloto em duas empresas, o qual proporcionou novas adequações em função de sua extensão e da linguagem utilizada, que, nesse primeiro momento, causou dúvidas por parte dos respondentes.

O questionário final ficou estruturado em três blocos. O primeiro deles relativo à identificação da empresa, incluindo o porte, a região e o setor, dentre outras informações relevantes. O segundo bloco referiu-se às ações e políticas de gestão ambiental desenvolvidas pela empresa, e o terceiro bloco destinou-se à avaliação dos aspectos determinantes das estratégias de gestão ambiental. As questões (fechadas e abertas) foram formuladas de forma a possibilitar que o respondente pudesse assinalar mais de uma opção. Não houve adoção de escalas. É importante salientar que o apoio da FIESC foi explicitado em todos os contatos iniciais com as empresas. Adicionalmente, atentou-se para a preocupação em elaborar um ofício explicando às empresas a importância da pesquisa, o que foi realizado em conjunto com a FIESC, também interessada nos seus resultados.

A população da pesquisa consistiu nas empresas ca- 
dastradas na base de dados da FIESC, em seus diversos tamanhos e setores de atuação. A escolha do segundo setor - atividade industrial - se deu em função de seu impacto e importância na economia do estado de Santa Catarina e do impacto de suas ações no meio ambiente. O tamanho das empresas foi caracterizado a partir do número de empregados. Foram enviados questionários a 2.000 empresas (810 de grande porte, 642 de médio porte e 452 de pequeno porte), 92 dos quais retornaram, apesar de os contatos com as empresas terem sido frequentes e contínuos. Foram descartados 4 questionários em função de problemas no preenchimento. Assim, 88 empresas foram incluídas na etapa seguinte, de análise. Apesar de o percentual de respondentes ter sido pequeno, seu número absoluto ainda coloca esta pesquisa como uma das maiores já realizadas no país com essa abordagem. Das empresas pesquisadas, 40 são grandes empresas. Foram agrupados os dados relativos às pequenas e médias, totalizando 48 PMEs, que foram comparadas às grandes empresas. Assim, tem-se nesta pesquisa uma amostra não probabilística, que pode ser classificada como uma amostra por acessibilidade.

Os questionários e os dados deles extraídos foram processados com o auxílio do software Sphinx. Para a análise dos dados, inicialmente procedeu-se a uma análise descritiva. A seguir, conduziu-se o estudo das relações entre as variáveis estudadas, utilizando-se a análise de correspondência múltipla (GREENACRE, 1987) das seguintes variáveis não paramétricas: tamanho, setor, mercado de atuação, presença de políticas de gestão ambiental integradas às demais políticas da organização, práticas de GA e aspectos determinantes das estratégias de GA, internos e externos. A variável independente nessa análise foi o porte das empresas.

A análise de correspondência múltipla (ACM) utilizada neste artigo é um método estatístico que permite a análise das informações contidas em uma tabela de contingência, representando simultaneamente as categorias (linhas e colunas) da tabela sobre um gráfico (mapa de perfis), na dimensão reduzida, por meio de pontos. A análise de correspondência múltipla é uma técnica adequada para analisar dados multivariados, ou seja, quando há um número grande de variáveis (COLDEBELLA, 2000). Essa técnica emprega uma tabela de contingência, que é a tabulação cruzada de duas variáveis categóricas. Os dados não métricos são transformados em um nível métrico, com redução dimensional (análogo à análise fatorial) e mapeamento perceptual (semelhante à análise multidimensional) (HAIR JR, J. F; R. E. ANDERSON; TATHAM, R. L; BLACK, W. C.). Assim, as percepções de respon- dentes quanto às variáveis dependentes (representadas nas figuras por quadrados e pontos cinza-claros), como, por exemplo, os aspectos determinantes das estratégias de GA, puderam ser tabuladas no cruzamento com a variável 'tamanho' da empresa (representada por quadrados cinza-escuros), indicando quantas empresas que percebem cada aspecto recaem em cada categoria de tamanho. Por meio de análise de correspondência, a associação ou correspondência de percepções de diferentes aspectos da GA e diferentes características daquelas empresas que percebem aquele fator é então mostrada em um mapa bidimensional de aspectos de características das empresas respondentes. Aspectos percebidos como semelhantes são colocados próximos um dos outros. Assim, a associação entre as variáveis é determinada pela proximidade das categorias da variável 'tamanho' às posições dos fatores percebidos nas demais variáveis. Desse modo, a análise de correspondência fornece uma representação multivariada de interdependência para dados não métricos (HAIR JR, J. F; ANDERSON, R. E; TATHAM, R. L; BLACK, W. C.), possibilitando a comparação do comportamento das variáveis dependentes entre as grandes e as pequenas e médias empresas.

\section{APRESENTAÇÃO DOS RESULTADOS}

Os dados a seguir apresentam a caracterização das 88 empresas pesquisadas, distribuídas nos seguintes setores: Complexo Agroindustrial, que inclui os setores de alimentos e bebidas; Complexo Eletrometalomecânico, que engloba metalurgia, mecânica, material elétrico e transportes; Complexo Têxtil, que inclui o setor têxtil e o de vestuário; Complexo Florestal, referente aos setores de mobiliário, madeira, papel e celulose; Complexo Tecnológico; e Complexo Mineral (metálicos e não metálicos). Os dados das pequenas e médias empresas foram agrupados, caracterizando as PMEs. Ressalta-se que os dados apresentados nas tabelas exibem as porcentagens das respostas relacionadas com a quantidade de citações e não com o número de observações. Isso é especialmente importante nas questões para as quais o respondente pôde assinalar mais de uma opção, como no caso das práticas de gestão ambiental (GA) adotadas e dos fatores determinantes internos e externos da adoção da GA. Os totais das tabelas referem-se ao percentual sobre o total dos respondentes, ou seja, 88 empresas. A ordem das categorias nas tabelas respeitou a frequência das respostas, ou seja, as categorias foram distribuídas em ordem decrescente em relação às respostas obtidas. 
Caracterização das empresas participantes da amostra da pesquisa de acordo com seu tamanho, segmento de atividade (setor) e mercado de atuação

A Tabela 1, que se segue, ilustra o total das empresas participantes da pesquisa, segundo o porte (tamanho) e o segmento de atividade, de acordo com a classificação da FIESC.

Das empresas participantes desta pesquisa, mais de $60 \%$ concentram-se nos setores florestal, eletrometalomecânico e têxtil, que, juntamente com as empresas agroindustriais, representam uma parcela importante do parque industrial do estado e do país. A indústria de transformação de Santa Catarina é a quarta do país em número de empresas e a quinta em quantidade de trabalhadores.

Das empresas pesquisadas, mais da metade atua também no mercado internacional, conforme pode ser verificado na Tabela 2.

O que chama a atenção é o número de empresas pequenas e médias que se internacionalizou (50\%), sendo praticamente igual ao das grandes empresas nesta amostra. No estado de Santa Catarina estão situadas indústrias importantes e de destaque tanto na América Latina como no mundo. Santa Catarina também está entre os maiores exportadores do país. Em 2008, as vendas para o mercado internacional foram de US\$ 8,3 bilhões, $4,2 \%$ do total exportado pelo Brasil, o que lhe possibilitou a nona posição no nível nacional e permitiu um saldo positivo de US\$ 305 milhões na balança comercial. Os principais mercados de destino dos produtos catarinenses em 2008 foram Estados Unidos (13,5\%), Japão (6,8\%), Argentina $(6,7 \%)$ e Países Baixos [Holanda] (6,6\%). O setor industrial possui uma participação de $61 \%$ nas exportações do estado (FIESC, 2009), sendo que nestas há uma expressiva representação das PMEs.

\section{Políticas de gestão ambiental, práticas adotadas e gestão dos recursos naturais}

A Tabela 3 exibe as respostas relativas à pergunta por meio da qual se procurou verificar se as empresas tinham políticas de gestão ambiental e como elas se articulavam com as demais políticas da organização. Os percentuais obtidos demonstram que, entre as grandes empresas, a presença de políticas de gestão ambiental integradas com as demais políticas da organização figura em $45 \%$ das empresas. Isso significa que mais de $50 \%$ das grandes empresas não possuem políticas de GA integradas, o que parece um número alto, considerando o porte das empresas. Tal constatação refuta os argumentos de Abreu e outros (2008), GonzálezBenito e González-Benito (2006) e Christmann e Taylor (2001), segundo os quais as grandes empresas possuem uma escala tal que permite que sua gestão se torne indivisível da GA. Por outro lado, observa-se que entre as

Tabela 1 - Percentual das empresas segundo o porte

\begin{tabular}{|l|c|c|c|}
\hline \multicolumn{1}{|c|}{ SEGMENTO DE ATIVIDADE/TAMANHO } & GRANDES & PMES & TOTAL \\
\hline Complexo Florestal & $20,00 \%$ & $27,10 \%$ & $23,55 \%$ \\
\hline Complexo Eletrometalomecânico & $15,00 \%$ & $25,00 \%$ & $20,00 \%$ \\
\hline Complexo Têxtil & $27,50 \%$ & $14,60 \%$ & $21,05 \%$ \\
\hline Complexo Agroindustrial & $15,00 \%$ & $14,60 \%$ & $14,80 \%$ \\
\hline Outros & $10,00 \%$ & $6,30 \%$ & $8,15 \%$ \\
\hline Complexo Tecnológico & $7,50 \%$ & $8,30 \%$ & $7,90 \%$ \\
\hline Complexo Mineral & $5,00 \%$ & $4,20 \%$ & $4,60 \%$ \\
\hline TOTAL & $100 \%$ & $100 \%$ & $100 \%$ \\
\hline
\end{tabular}

Tabela 2 - Percentual das empresas segundo o porte e a área de atuação

\begin{tabular}{|l|c|c|c|}
\hline \multicolumn{1}{|c|}{ ÁREA DE ATUAÇÃO/TAMANHO } & GRANDES & PMES & TOTAL \\
\hline Mercado Interno & $47,5 \%$ & $50,0 \%$ & $48,75 \%$ \\
\hline Mercado interno e externo & $52,5 \%$ & $50,0 \%$ & $51,25 \%$ \\
\hline TOTAL & $100 \%$ & $100 \%$ & $100 \%$ \\
\hline
\end{tabular}


grandes empresas não há ausência de política ou prática ambiental, ainda que $25 \%$ delas não tenham registro formal das ações e $20 \%$ apresentem políticas de GA isoladas das demais políticas da organização.

Nas PMEs, as respostas distribuem-se, principalmente, entre políticas de GA integradas às demais políticas da organização $(27,1 \%)$, presença de políticas sem registros formais $(27,1 \%)$ e a ausência de políticas com a adoção de práticas não sistematizadas (25,0\%). Nas PMEs, apenas $4,2 \%$ afirmam não ter política ou prática ambiental.
O mapa de correspondência (Figura 1) revela que a categoria "não, nenhuma política ou prática ambiental" está mais distante do centroide dos pontos e localizada no quadrante direito do mapa, sugerindo que somente uma pequena proporção dos respondentes pertencentes às PMEs não possuem nenhuma política ou prática ambiental. Observa-se também uma associação das grandes empresas com a presença de políticas integradas, e das PMEs com a adoção de práticas não sistematizadas e com a ausência de registro formal das ações de GA.

Tabela 3 - Percentual das empresas segundo o porte e a existência de política de política de gestão ambiental

\begin{tabular}{|c|c|c|c|}
\hline POLÍTICA DE GESTÃO AMBIENTAL/TAMANHO & GRANDES & PMES & TOTAL \\
\hline Sim, integrada com as demais políticas da organização & $45,00 \%$ & $27,10 \%$ & $36,05 \%$ \\
\hline Sim, mas não há registro formal das ações & $25,00 \%$ & $27,10 \%$ & $26,05 \%$ \\
\hline Não, mas adotam práticas não sistematizadas & $10,00 \%$ & $25,00 \%$ & $17,50 \%$ \\
\hline Sim, isolada das demais políticas da organização & $20,00 \%$ & $8,30 \%$ & $14,15 \%$ \\
\hline Não resposta & $0,00 \%$ & $8,30 \%$ & $4,15 \%$ \\
\hline Não, nenhuma política ou prática ambiental & $0,00 \%$ & $4,20 \%$ & $2,10 \%$ \\
\hline TOTAL & $100 \%$ & $100 \%$ & $100 \%$ \\
\hline
\end{tabular}

Figura 1 - Análise de correspondência múltipla das empresas segundo o porte e a existência de política de gestão ambiental

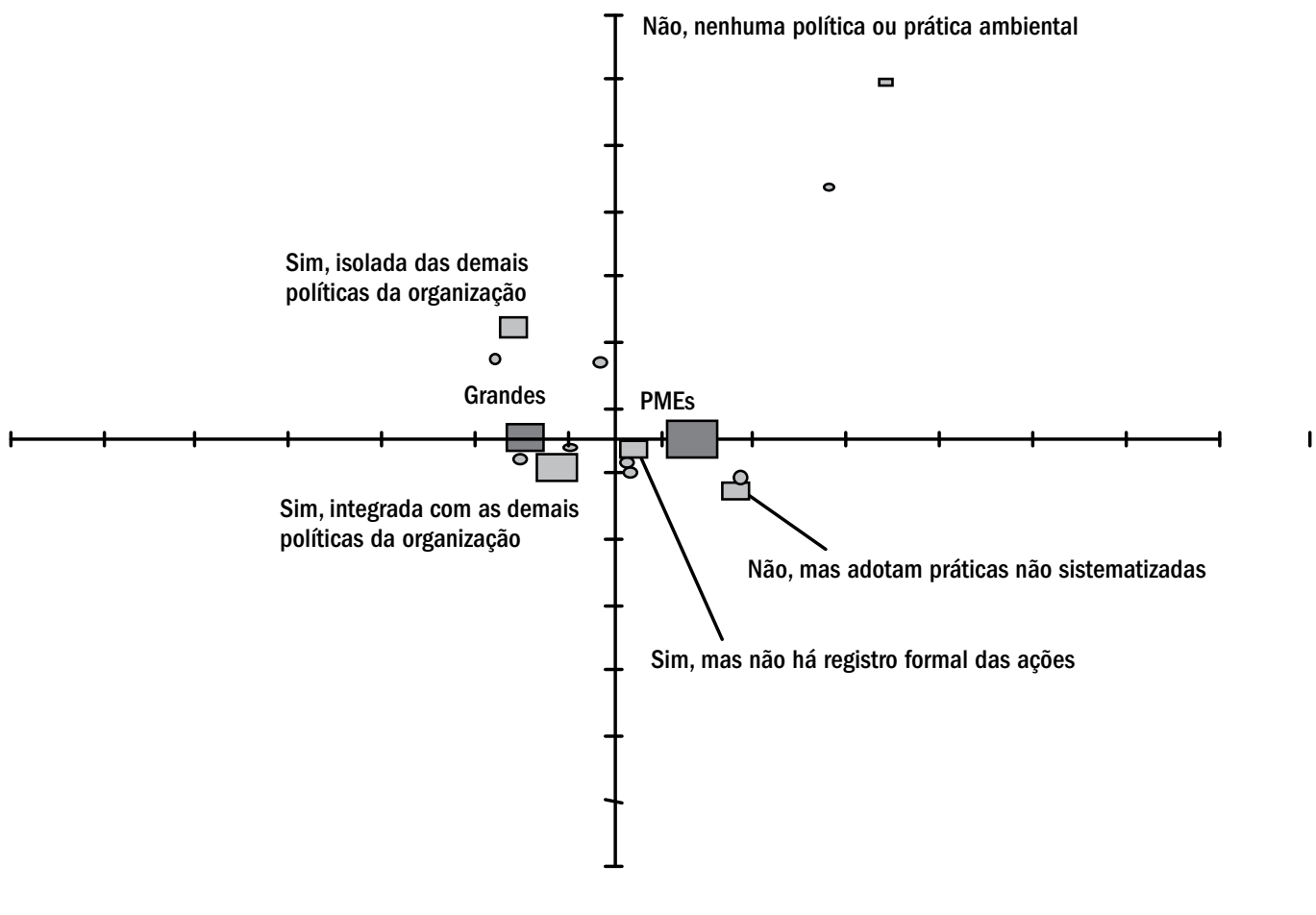


Conforme a Tabela 4 , a seguir, a principal prática adotada pelas indústrias, independentemente do tamanho ao qual pertencem, é a reciclagem, citada por mais de $80 \%$ da amostra total. A produção mais limpa também está significativamente presente nas empresas, especialmente nas de grande porte, sugerindo uma melhor utilização das matérias-primas, levando a uma otimização dos processos produtivos pela minimização dos resíduos e ao aumento da eficiência. Mais da metade das grandes empresas possuem certificação ambiental, sendo que o mesmo percentual $(52,5 \%)$ dessas empresas realiza auditoria ambiental, realidade não confirmada entre as PMEs.

Apesar da existência de ações ambientais importantes, a pesquisa aponta para a predominância de práticas relacionadas ao produto (GUPTA, 1994), como a reciclagem. Mesmo assim, a reciclagem pode variar desde ações mais simples, como a reciclagem de papel, até ações mais complexas, como a reciclagem de alumínio e de resíduos perigosos. Já práticas relacionadas ao processo (GUPTA, 1994), como a avaliação do ciclo de vida do produto e a logística reversa, figuram entre as menos adotadas por todas as empresas, independentemente do tamanho, ainda que a primeira apresente maior percentual entre as PMEs.

O mapa de correspondência (Figura 2) revela que as práticas desenvolvidas pelas empresas encontram-se todas agrupadas próximo ao centroide dos pontos, ou ao ponto zero, revelando a ausência de correlação entre as práticas de GA e o porte das empresas, ou seja, as práticas são homogêneas, sugerindo um isomorfismo entre as empresas.

A partir da análise das práticas de gestão ambiental desenvolvidas, constata-se, portanto, uma baixa consciência na produção e nos métodos e processos operacionais desenvolvidos pelas empresas estudadas. Tais práticas parecem refletir estratégias voltadas para a prevenção da poluição e para o planejamento do produto em detrimento de estratégias de desenvolvimento sustentável (HART, 1995) ou voltadas para uma abordagem estratégica (BARBIERI, 2004) que envolveria toda a cadeia produtiva, inclusive ações corretivas, preventivas e antecipatórias. Nota-se, neste caso, o baixo percentual de empresas que se preocupam com a avaliação do ciclo de vida do produto.

Conforme pode ser observado na Tabela 5 , quando perguntado às empresas como elas gerenciam seus recursos naturais, mais da metade das de grande porte afirmam adotar metas de redução, monitorar a utilização dos recursos naturais por meio de indicadores e adotar programas de gestão.

Já entre as PMEs, esse percentual diminui, sendo que $43 \%$ das empresas desse porte afirmam não possuir ações nesse sentido, contra apenas $12,5 \%$ das grandes. Tais resultados parecem relacionar-se ao fato de as grandes empresas possuírem políticas de GA (90\%) em número maior do que as PMEs (62,5\%), mesmo que isoladas.

Tabela 4 - Práticas de gestão ambiental adotadas segundo o porte das empresas

\begin{tabular}{|l|l|l|l|}
\hline \multicolumn{1}{|c|}{ PRÁTICA ADOTADA/TAMANHO } & GRANDES & PMES & TOTAL \\
\hline Reciclagem & $92,50 \%$ & $72,90 \%$ & $82,70 \%$ \\
\hline Produção + Limpa & $60,00 \%$ & $41,70 \%$ & $50,85 \%$ \\
\hline Áreas de reflorestamento/preservação & $57,50 \%$ & $37,50 \%$ & $47,50 \%$ \\
\hline Certificação Ambiental & $52,50 \%$ & $35,40 \%$ & $43,95 \%$ \\
\hline Auditoria Ambiental & $52,50 \%$ & $16,70 \%$ & $34,60 \%$ \\
\hline Eficiência Energética & $47,50 \%$ & $14,60 \%$ & $31,05 \%$ \\
\hline Avalia riscos socioambientais em empreendimentos & $30,00 \%$ & $12,50 \%$ & $21,25 \%$ \\
\hline Balanço social (Passivo Ambiental) & $22,50 \%$ & $2,10 \%$ & $12,30 \%$ \\
\hline Avaliação do Ciclo de vida do Produto & $7,50 \%$ & $12,50 \%$ & $10,00 \%$ \\
\hline Apoio a ONGs ambientais & $17,50 \%$ & $4,20 \%$ & $10,85 \%$ \\
\hline Seguro Ambiental & $10,00 \%$ & $2,10 \%$ & $6,05 \%$ \\
\hline Compensação ambiental & $10,00 \%$ & $0,00 \%$ & $5,00 \%$ \\
\hline Ecodesign & $7,50 \%$ & $2,10 \%$ & $4,80 \%$ \\
\hline Logística Reversa & $5,00 \%$ & $4,20 \%$ & $4,60 \%$ \\
\hline Mercado de Créditos de Carbono (MCC) & $10,00 \%$ & $0,00 \%$ & $5,00 \%$ \\
\hline
\end{tabular}


O mapa de correspondência múltipla (Figura 3), no que tange à gestão dos recursos naturais, revela uma dispersão em relação às opções de resposta. O monitoramento da gestão ambiental a partir de indicadores e a adoção de programas de gestão têm maior associação com as grandes empresas.

Já na amostra das PMEs, a proximidade a partir do eixo vertical sugere uma maior associação destas com a ausência de ações específicas de gestão dos recursos naturais, embora também com a adoção de metas de redução.

\section{Fatores determinantes das estratégias de gestão ambiental}

Os dados da Tabela 6 referem-se aos fatores internos determinantes das estratégias de GA nas empresas estudadas.
Observa-se que o comprometimento dos colaboradores foi o fator mais citado nas duas categorias de tamanho, seguido do apoio dos gestores e da disponibilidade financeira. Ressalta-se que os valores/história de vida da organização foram citados pelas empresas, na opção "outros", como um fator determinante interno por $55 \%$ das grandes e 39,6\% das PMEs.

A importância dos valores da organização como um fator determinante interno das estratégias de GA das empresas é destacada por Jabbour e Santos (2006), que veem esses valores como sendo um fator relativo à área de recursos humanos responsável pelo encorajamento de uma cultura organizacional voltada para as questões ambientais. Esse fator também se relaciona ao apoio dos gestores e ao comprometimento dos colaboradores, uma

Figura 2 - Análise de correspondência múltipla das empresas segundo o porte e as práticas de gestão ambiental adotadas

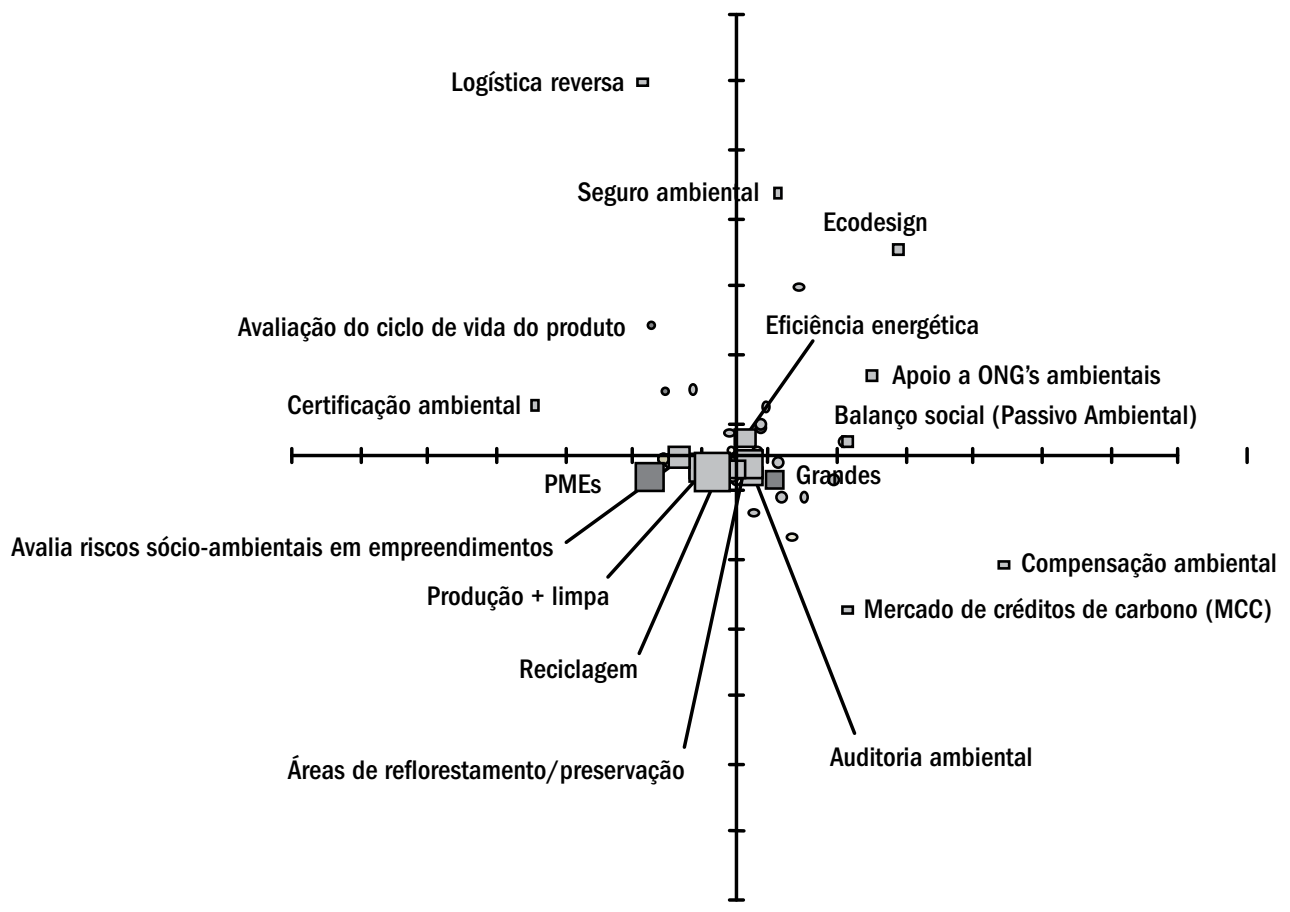

Tabela 5 - Gestão dos recursos naturais e o porte das empresas

\begin{tabular}{|c|c|c|c|}
\hline GESTÃO DE RECURSOS NATURAIS/TAMANHO & GRANDES & PMES & TOTAL \\
\hline Adota metas de redução & $52,50 \%$ & $35,40 \%$ & $43,95 \%$ \\
\hline Monitora com indicadores & $62,50 \%$ & $10,40 \%$ & $36,45 \%$ \\
\hline Adota programas de gestão & $52,50 \%$ & $16,70 \%$ & $34,60 \%$ \\
\hline Não possui ação específica & $12,50 \%$ & $43,80 \%$ & $28,15 \%$ \\
\hline
\end{tabular}


vez que a cultura organizacional se fortalece a partir da integração entre os membros da organização, sendo influenciada pelos valores e história de vida tanto dos fundadores e gestores quanto dos demais colaboradores. Outro aspecto citado como determinante interno é a disponibilidade financeira das empresas, principalmente entre as grandes empresas, o que pode sugerir um estágio de GA superior nas empresas com melhor desempenho financeiro.
A imagem do mapa de correspondência múltipla (Figura 4) também revela que a distância entre os pontos relativos aos fatores listados e a categoria das empresas analisadas não caracteriza propriamente uma diferença significativa entre o porte das empresas e os aspectos internos percebidos como determinantes. Contudo, observa-se que a disponibilidade financeira e a integração da GA ao planejamento estratégico das empresas estão mais próximas das grandes empresas.

Figura 3 - Análise de correspondência múltipla segundo o porte e a gestão dos recursos naturais

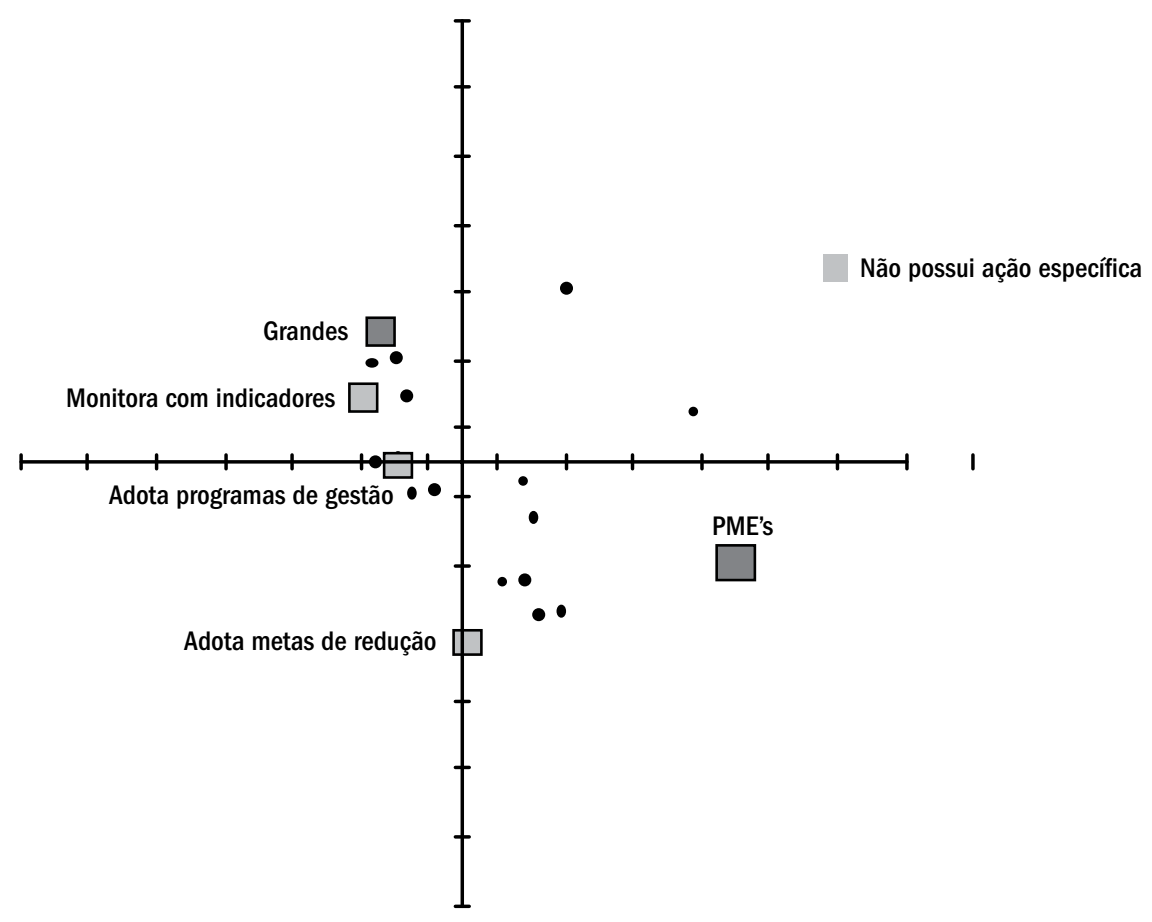

Tabela 6 - Fatores determinantes internos por porte das empresas

\begin{tabular}{|c|c|c|c|}
\hline FATORES DETERMINANTES INTERNOS/TAMANHO & GRANDES & PMES & TOTAL \\
\hline Comprometimento dos colaboradores & $75,00 \%$ & $54,20 \%$ & $64,60 \%$ \\
\hline Apoio dos gestores & $70,00 \%$ & $52,10 \%$ & $61,05 \%$ \\
\hline Disponibilidade Financeira & $75,00 \%$ & $35,40 \%$ & $55,20 \%$ \\
\hline Valores/ história da organização & $55,00 \%$ & $39,60 \%$ & $47,30 \%$ \\
\hline Integração ao planejamento estratégico & $47,50 \%$ & $20,80 \%$ & $34,15 \%$ \\
\hline Investimentos na área de P \& D & $30,00 \%$ & $16,70 \%$ & $23,35 \%$ \\
\hline Capacidade de investimento na área & $5,00 \%$ & $6,30 \%$ & $5,65 \%$ \\
\hline
\end{tabular}


Constata-se, também, que o percentual de empresas que percebem a integração ao planejamento estratégico como um aspecto determinante interno $(47,5 \%)$ é bastante próximo do percentual das empresas que afirmam possuir políticas de GA integradas às demais políticas da organização (45\%).

A partir da comparação entre as empresas de diferentes tamanhos e os fatores externos percebidos como determinantes das estratégias de gestão ambiental, pode- se verificar, na Tabela 7, que a exigência da sociedade (clientes), as regulamentações do governo, a adequação aos padrões normativos e a concorrência aparecem como os fatores externos mais citados pelo total das empresas da amostra estudada.

O mapa de correspondência múltipla gerado a partir dos dados relativos aos fatores externos (Figura 5) não permite determinar uma relação entre o tamanho das empresas e os fatores externos que influenciam a sua gestão ambiental.

Figura 4 - Análise de correspondência múltipla dos fatores determinantes internos por porte das empresas

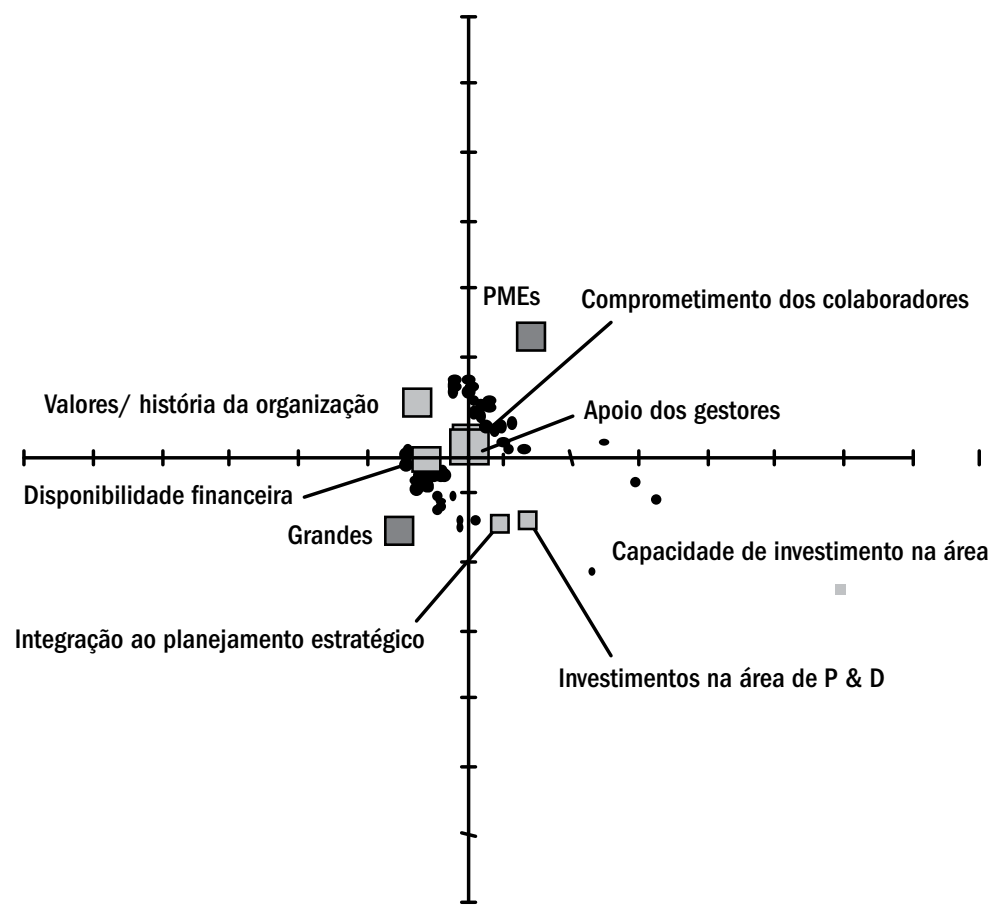

Tabela 7 - Fatores determinantes externos por porte das empresas

\begin{tabular}{|c|c|c|c|}
\hline FATORES DETERMINANTES EXTERNOS/TAMANHO & GRANDES & PMES & TOTAL \\
\hline Exigência da sociedade/clientes & $67,50 \%$ & $52,10 \%$ & $59,80 \%$ \\
\hline Regulamentações (Governo) & $52,50 \%$ & $45,80 \%$ & $49,15 \%$ \\
\hline Adequação a padrões normativos (Órgãos certificadores) & $50,00 \%$ & $39,60 \%$ & $44,80 \%$ \\
\hline Tendência do mercado (concorrência) & $52,50 \%$ & $37,50 \%$ & $45,00 \%$ \\
\hline Expansão de mercado (novos clientes) & $47,50 \%$ & $35,40 \%$ & $41,45 \%$ \\
\hline Obtenção de crédito (financiadores) & $30,00 \%$ & $8,30 \%$ & $19,15 \%$ \\
\hline Pressão de organizações ambientalistas & $10,00 \%$ & $6,30 \%$ & $8,15 \%$ \\
\hline
\end{tabular}


A imagem do mapa apresenta uma concentração muito forte de todas as empresas em torno dos mesmos fatores. Observa-se também que, enquanto as regulamentações governamentais parecem ser mais significativas para as PMEs, a concorrência e a obtenção de crédito são mais percebidas pelas empresas de grande porte.

\section{DISCUSSÃO E CONSIDERAÇÕES FINAIS}

O presente trabalho se propôs a analisar os fatores determinantes das estratégias de gestão ambiental das empresas industriais catarinenses de acordo com seu porte. Para isso, antes de analisar os fatores em si, foram apresentados dados relativos à amostra das empresas estudadas, revelando os setores de atuação, os mercados atendidos (externo e interno), a presença de políticas de gestão ambiental, as práticas adotadas e a forma de gestão dos recursos naturais.

A principal contribuição do estudo foi a agregação de dados da gestão ambiental de empresas de diferentes portes por meio da análise de correspondência múltipla, inclusive as pequenas e médias, e a partir de uma visão estratégica, o que se mostra ainda incipiente na literatura especializada (LEE, 2009). Isso é especialmente relevante no caso brasileiro, quando uma parcela representativa da economia depende das PMEs e, apesar disso, a grande maioria das pesquisas ainda gira em torno das grandes empresas. Por outro lado, essa mesma contribuição transforma-se na principal limitação da pesquisa. Na medida em que se agregam resultados, tem-se uma fotografia estática da situação das empresas, perdendo-se de vista os processos subjacentes, tais como o aprendizado e os esforços envidados na transformação da gestão ambiental dessas organizações. Estudos qualitativos e longitudinais permitiriam uma melhor compreensão desses processos e do grau de investimentos e aculturação das questões ambientais nas empresas.

O estudo revela que pelo menos $50 \%$ das empresas de ambas as categorias (grande porte e PMEs) atuam no mercado internacional, e que uma parcela significativa adota políticas de gestão ambiental (90\% das grandes e 62,5\%

Figura 5 - Análise das correspondências múltiplas dos fatores determinantes externos por porte das empresas

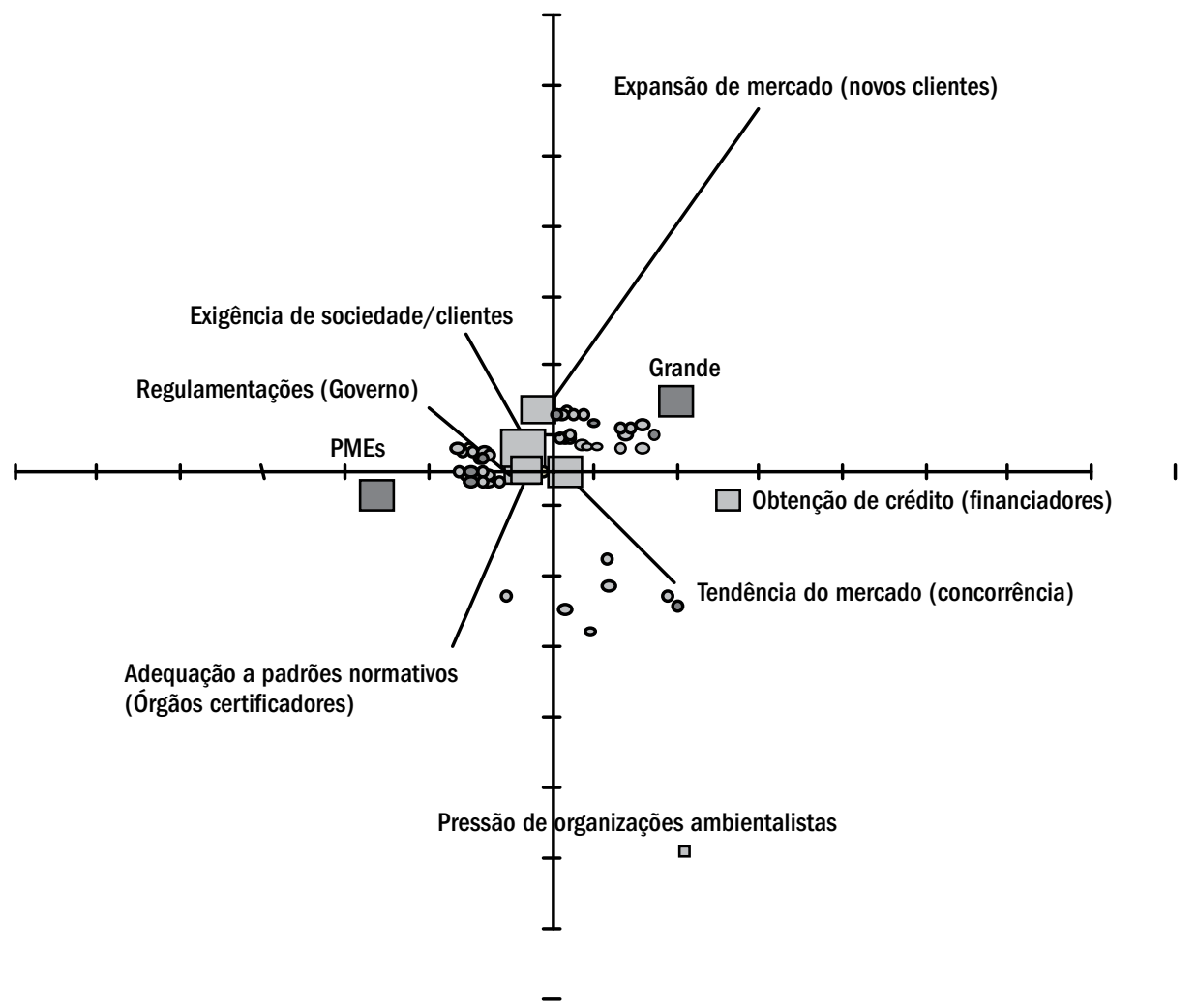


das PMEs), sendo que as políticas de GA integradas às demais políticas da organização aparecem associadas às grandes empresas (com percentual de $45 \%$ contra $27,1 \%$ das PMEs). Apesar disso, entre as práticas de GA adotadas pelas empresas, observou-se uma homogeneidade entre os diferentes tamanhos e uma predominância de práticas relacionadas aos produtos, em detrimento das práticas relacionadas aos processos, que focam, com foco interno, o desenvolvimento de novos processos operacionais e tecnologias. Assim, pode-se afirmar que o estágio da gestão ambiental vista como um processo contínuo de melhoria das políticas e programas ambientais (GUPTA, 1994) ainda não predomina nas empresas industriais catarinenses, pelo menos na amostra estudada. Esse fato é curioso, na medida em que refuta as assertivas de Abreu e outros (2008), González-Benito e González-Benito (2006) e Christmann e Taylor (2001), e os próprios pressupostos dos autores deste artigo, que pressupunham práticas mais avançadas por parte das grandes empresas. Embora os dados da pesquisa não representem a totalidade das empresas catarinenses, não tornando possível a generalização dos resultados, eles permitem aos gestores ter uma noção do estágio em que se encontra uma parcela significativa das empresas, auxiliando-os a estabelecer estratégias e metas de forma a superar os atuais obstáculos na promoção de ações ambientais mais proativas. Da mesma forma, o estudo esclarece que, apesar do discurso a favor do meio ambiente, as práticas adotadas por muitas empresas nem sempre superam tais retóricas, chamando a atenção dos gestores para a necessidade de compatibilizar o discurso com a prática, as estratégias com as ações, ou a imagem com a identidade organizacional, sincronismos que tendem a ser, cada vez mais, exigidos pela sociedade global.

No que tange aos fatores internos determinantes das estratégias de GA, constatou-se que o comprometimento dos colaboradores foi o fator mais citado nas duas categorias de tamanho, seguido do apoio dos gestores. Este fato corrobora as assertivas de Donaire (1995) sobre a importância da contribuição dos recursos humanos na mitigação dos impactos ambientais por parte das empresas, fato não confirmado pela pesquisa de Jabbour, Santos e Nagano (2009), cujos resultados revelaram que um conjunto significativo das dimensões de recursos humanos tende a não se relacionar com a gestão ambiental empresarial. Tais achados também enfatizam a necessidade de estudos que aprofundem as análises sobre o retorno do aprendizado e do investimento em capacitação e sensibilização para as questões ambientais por parte dos gestores empresariais, de modo a corresponder às expectativas das partes interessadas. Da mesma forma, ressalta aos geren- tes a importância do envolvimento da alta direção, dos valores e da cultura corporativa no desenvolvimento de uma gestão ambiental mais efetiva.

Os resultados encontrados para essa amostra revelam, ainda, que o fator externo percebido como de maior relevância para as organizações de qualquer tamanho é, de fato, a pressão da sociedade. Essa conclusão, somada à importância das regulamentações governamentais, à adequação a padrões normativos e à concorrência, confirma as pesquisas de Darnal, Henriques e Sadorsky (2008), Eiadat, Kelly, Roche e Eyadat (2008), Lee e Rhee (2006), González-Benito e González-Benito (2006), Sharma (2000), Bansal e Roth (2000), Henriques e Sadorsky (1999), e Berry e Rondinelli (1998), reafirmando a ideia de que as organizações parecem movimentar-se em direção à gestão ambiental por pressões miméticas, coercitivas e normativas. Observa-se também que são os stakeholders primários os maiores responsáveis pelas pressões sentidas pelos gestores. Por outro lado, stakeholders secundários, tais como as ONGs, exercem pouca influência nas ações ambientais desenvolvidas pelas empresas estudadas, representando menos de $10 \%$ das respostas. Tal constatação corrobora as pesquisas de González-Benito e González-Benito (2006), e Henriques e Sadorsky (1999), e refuta Souza (2002), que considera a sociedade civil organizada, principalmente os movimentos ambientalistas, como um dos mais importantes stakeholders das empresas no que se refere às questões ambientais. Essas constatações trazem à tona importantes reflexões sobre o papel do governo tanto na definição de regulamentações ambientais impostas às organizações quanto na promoção de conhecimento e divulgação acerca dessas questões dirigidas à sociedade em geral. Na medida em que se revelam as pressões da sociedade e as regulamentações governamentais como os aspectos externos de maior relevância na determinação das estratégias de gestão ambiental por parte das empresas, é certo que o papel do governo na definição dessas políticas seja de vital importância.

Em função de tudo o que aqui foi discutido, percebese que as estratégias de GA desenvolvidas pelas empresas pesquisadas apresentam características dos três estágios vistos nos fundamentos teóricos do artigo independentemente de seus portes, e que suas estratégias, nesse sentido, decorrem, principalmente, de pressões normativas, coercitivas e miméticas do ambiente institucional ao qual as organizações estão submetidas. Contudo, as empresas parecem estar se deslocando na direção de comportamentos mais proativos, principalmente as grandes empresas, pois uma parcela significativa já apresenta 
políticas de GA integradas às demais políticas da organização e o monitoramento da GA a partir de indicadores. Isso pode significar um esforço contínuo por parte das empresas para incluir em seus processos decisórios a alocação de recursos direcionados às questões ambientais, abrindo um amplo leque de pesquisas que busquem verificar esse movimento. Assim, pesquisas que incluam análises comparativas longitudinais entre os diversos tamanhos de empresas e entre os diferentes setores industriais seriam bem-vindas. Da mesma forma, estudos de caso que permitissem a análise dos processos organizacionais subjacentes à gestão ambiental envolvendo a aprendizagem, os recursos humanos, a estruturação e a cultura organizacional também se caracterizariam em importantes contribuições, especialmente no que tange às pequenas e médias empresas.

Pressupõe-se, conforme constatado por Sharma (2000), que as escolhas estratégicas que as empresas conduzem em relação à GA relacionam-se com a interpretação que seus gestores têm do ambiente e de como esse ambiente influencia essas decisões, como uma oportunidade ou ameaça, como benefício ou como custo. Todavia, a similaridade encontrada entre as ações empresariais no que tange à GA pode ser explicada pela recursividade entre o ambiente e a cognição dos gestores, conduzindo a políticas, estratégias e práticas que se assemelham em função de o seu ambiente institucional também apresentar similaridades. Assim, esses achados podem estar relacionados ao contexto no qual as estratégias empresariais emergem, sugerindo a necessidade de novas pesquisas que busquem comparar o comportamento ambiental das empresas em diferentes contextos, sejam eles municipais, estaduais e até mesmo nacionais.

\section{REFERÊNCIAS}

ABREU, M. C. S. Modelo de avaliação da estratégia ambiental: uma ferramenta para a tomada de decisão. 2001. 218 p. Tese de Doutorado em Engenharia de Produção, Programa de Pós-Graduação em Engenharia de Produção da Universidade Federal de Santa Catarina, Florianópolis, 2001.

ABREU , M. C. S; SILVA FILHO, J. C. L; OLIVEIRA, B. C; HOLANDA JÚNIOR, F. L. Perfis estratégicos de conduta social e ambiental: estudos na indústria têxtil nordestina. Gestão da Produção, v. 15, n. 1, 2008.

ARAGÓN-CORRREA, A; SHARMA, S. A contingent resource-based view of proactive corporate environmental strategy. Academy of Management Review, v. 28, n. 1, p. 71-88, 2003.
ARAGÓN-CORRREA, A; RUBIO-LÓPEZ, E. A. Proactive corporate environmental strategies: myths and misunderstandings. Longe Range Planning, v. 40, p. 357-381, 2007.

BANSAL, P; ROTH, K. Why companies go green: a model of ecological responsiveness. Academy of Management Journal, v. 43, n. 4, p. 717-736, 2000

BARBIERI, J. C. Gestão ambiental empresarial: conceitos, modelos e instrumentos. São Paulo: Saraiva, 2004.

BERRY, M. A; RONDINELLI, D. A. Proactive corporate environmental management: a new industrial revolution. Academy of Management Executive, v. 12, n. 2,1998

CALLENBACH, E. Gerenciamento ecológico = ecomanagement: guia do Instituto Elmwool de auditoria ecológica e negócios sustentáveis. São Paulo: Cultrix, c.1993.

CHRISTMANN, P; TAYLOR, G. Globalization and the environmental: determinants of firm self-regulation in China. Journal of International Business Studies, v. 32, n. 3, 2001

CLARK, W; DEMIRAG, I. Enron: the failure of corporate governance. Journal of Corporate Citizenship, p. 105-122, 2004.

COLDEBELLA, A. Análise de correspondência na identificação de variáveis associadas com intervalo entre partos em bovinos leiteiros. 2000. $104 \mathrm{p}$. Dissertação de Mestrado, Escola Superior de Agricultura Luiz de Queiroz da Universidade de São Paulo, São Paulo, 2000.

D'AVIGNON, A. L. A. Sistemas de gestão ambiental e normalização ambiental. Segmento da apostila utilizada no curso sobre Auditorias Ambientais da Universidade Livre do Meio Ambiente. Curitiba: ULMA, 1996.

DARNAL, N; HENRIQUES, I; SADORSKY, P. Do environmental management systems improve business performance in an international setting? Journal of International Management, v. 14, p. 364-376, 2008.

DIMAGGIO, P. J; POWELL, W. W. The iron cage revisited: institutional isomorphism and collective rationality in organizational fields. American Sociological Review, v. 48, p. 147-160, 1983.

DIMAGGIO, P. J. Constructing an organizational field as a professional project: US art museums, 1920-1940. In: POWELL, W. W; DIMAGGIO, P. J. The New Institutionalism in Organizational Analysis. London: University of Chicago Press, 1991.

DIMAGGIO, P. J; POWELL, W. W. Introduction. In: POWELL, W. W; DIMAGGIO, P. J. The New Institutionalism in Organizational Analysis London: University of Chicago Press, 1991.

DONAIRE, D. Gestão ambiental na empresa. São Paulo: Atlas, 1995. 
EIADAT, H; KELLY, A; ROCHE, F; EYADAT, Y. Green and competitive? An empirical test of the mediating role of environmental innovation strategy. Journal of World Business, v. 43, p. 131-145, 2008.

FEDERAÇÃO DAS INDÚSTRIAS DO ESTADO DE SANTA CATARINA. Santa Catarina em Dados. Unidade de Política Econômica e Industrial. Florianópolis: FIESC, 2009

FONSECA, V. S. A abordagem em estudos organizacionais: bases conceituais e desenvolvimentos contemporâneos. In: VIEIRA, M. M. F; CARVALHO, C. A. Organizações, instituições e poder no Brasil. Rio de Janeiro: Editora FGV, 2003

FORZA, C. Survey research in operations management: a process-based perspective. International Journal of Operations \& Production Management, United Kingdom, v. 22, n. 2, p. 152-194, 2002.

FREEMAN, R. E. Strategic Management: A Stakeholder Approach. Boston: Pitman, 1984.

GIDDENS, A. A constituição da sociedade. São Paulo: Martins Fontes, 2003

GONZÁLEZ-BENITO, J. G.; GONZÁLEZ-BENITO, O. G. A review of determinant factors of environmental proactivity. Business Strategy and the Environment, v.15, p. 87-102, 2006

GREENACRE, M. J; HASTIE, T. The geometric interpretation of correspondence analysis. Journal of de American Statistical Association, 82, p. 437-447, 1987.

GUPTA, M. C. Environmental management and its impacts on the operations function. International Journal of Operations and Production Management, v. 15, n. 8, 1994.

HAIR JR; BABIN, B; MONEY, A; SAMOUEL, P. Fundamentos de métodos de pesquisa em administração. Porto Alegre, Bookman, 2005.

HALL, R. H. Desarrollos recientes en teoría organizacional: una revisión. Ciencia y Sociedad, v. 15, n. 4, p. 376-411, 1990.

HALL, P; TAYLOR, R. As três versões do neoinstitucionalismo. Lua Nova, v. 58, n. 1, p. 193-223, 2003.

HART, S. L. The natural resource-based view of the firm. Academy of Management Review, v. 20, n. 4, p. 986-1014, 1995.

HENRIQUES, I; SADORSKY, P. The relationship between environmental commitment and managerial perceptions of stakeholder importance. Academy of Management Journal, v. 42, n. 1, p. 87-99, 1999.

HUNT, C. B; AUSTER, E. R. Proactive environmental management: avoiding the toxic trap. Sloan Management Review, EUA: Putnam, Hayes \& Bartlett, 1990.
ISO. International Organization for Standardization. NBR ISO 14.001: Sistemas de gestão ambiental - Especificação e diretrizes para uso. Rio de Janeiro: ABNT, 1996.

JABBOUR, C. J. C; SANTOS, F. C. A; NAGANO, M. S. Análise do relacionamento entre estágios evolutivos da gestão ambiental e dimensões de recursos humanos: estado da arte e survey em empresas brasileiras. Revista de Administração, São Paulo, v. 44, n. 4, p. 342-364, 2009

JABBOUR, C. J. C; SANTOS, F. C. A. The evolution of environmental management within organizations: toward a common taxonomy. Environmental Quality Mangement, 2006.

LEE, K-H. Why and how to adopt green management into business organizations? The case study of Korean SMEs in manufacturing industry Management Decision, v. 47, n. 7, 2009.

LEE, S.Y; RHEE, S. The change in corporate environmental strategies: a longitudinal empirical study. Management Decision, v. 45, n. 2, p. 196216,2006

MACHADO-DA-SILVA, C. L; FONSECA, V. S; FERNANDES, B. H. R Mudança e estratégia nas organizações: perspectivas cognitiva e institucional. In: VIEIRA, M. M. F; OLIVEIRA, L. M. B. Administração contemporânea: perspectivas estratégicas. São Paulo: Atlas, 1999.

MAIMON, D. Ecoestratégia nas empresas brasileiras: realidade ou discurso? RAE-revista de administração de empresas, São Paulo, v. 34, n. 4 p. 119-130, 1994

MEYER, J. W; SCOTT, W. R. Organizational Environments: Ritual and Rationality. Beverly Hills: Sage, 1983.

MEYER, J. W; ROWAN, B. Institutionalized organizations: formal structure as myth and ceremony. American Journal of Sociology, v. 83, n. 2, p. $340-363,1977$

MOLINA-AZORIN, J. F; CLAVER-CORTÉS, E; LOPEZ-GAMERO, R. J. T. Green management and financial performance: a literature review. Management Decision, v. 47, n. 7, 2009.

NASCIMENTO, L. F. Quando a gestão social e a gestão ambiental se encontram. In: ENCONTRO NACIONAL DA ASSOCIAÇÃO NACIONAL DOS PROGRAMAS DE PÓS-GRADUAÇÃO EM ADMINISTRAÇÃO, 39 2007, Rio de Janeiro. Anais Eletrônicos... Rio de Janeiro: ANPAD, 2007. $1 \mathrm{CD}-\mathrm{ROM}$

OGAWA, R. T. The institutional sources of educational reform: the case of school-based management. American Educational Research Journal, v. 31, n. 3, p. 519-548, 1994.

OLIVER, C. Strategic responses to institutional processes. Academy of management Review, v. 16, n. 1, p. 145-179, 1991. 
PERROW, C. Complex Organizations: A Critical Essay. New York: McGrawHill, 1986

PORTER, M. E; VAN DER LINDE, C. Green and competitive. Harvard Business Review, Sep-Oct, 1995.

REIS, L. F. S. S. D; QUEIROZ, S. M. P. Gestão ambiental em pequenas e médias empresas. Rio de Janeiro: Qualitymark, 2002.

ROHRICH, S. S; CUNHA, J. C. A Proposição de uma taxonomia para análise da gestão ambiental no Brasil. Revista de Administração Contemporânea, v. 8, n. $4,2004$.

SANCHES, C. S. Gestão ambiental proativa. RAE-revista de administração de empresas, v. 40, n.1, p. 76-87, 2000

SCOTT, W. R. Institutions and Organizations. 2. ed. London: Sage, 2001.

SCHENINI, P. C. (Org) Gestão empresarial socioambiental. Florianópolis: (s.n.), 2005.

SELZNICK, P. Institutionalism "old" and "new". Administrative Science Quarterly, v. 41, p. 270-277, 1996.
SCOTT, W. R. The adolescence of institutional theory. Administrative Science Quarterly, v. 32, n. 4, p. 493-511, Dec. 1987.

SHARMA, S. Managerial interpretations and organizational context as predictors of corporate choice of environmental strategy. Academy of Management Journal, v. 43, n. 4, p. 681-697, 2000

SHARMA, S; VREDENBERG, H. Proactive corporate environmental strategy and the development of competitively valuable organizational capabilities. Strategic Management Journal, v. 19, p. 729-753, 1998.

SOUZA, R. S. Evolução e condicionantes da gestão ambiental nas empresas. REAd, Edição Especial 30, v. 8 n. 6, nov-dez. 2002.

TACHIZAWA, T. Gestão ambiental e responsabilidade social corporativa: estratégias de negócios focadas na realidade brasileira. 4. ed. São Paulo: Atlas, 2007.

ZUCKER, L. G. Normal change or risk business: institutional effects on the "hazard" of change in hospital organizations, 1959-79. Journal of Management Studies, v. 24, n. 6, p. 671-700, 1987. 